\title{
Effect of cavity preparation techniques and different preheating procedures on microleakage of class $\mathrm{V}$ resin restorations
}

\author{
Emine Sirin Karaarslan ${ }^{1}$ \\ Aslihan Usumez ${ }^{2}$ \\ Bora Ozturk ${ }^{3}$ \\ Mehmet Ata Cebe
}

\begin{abstract}
Objectives: This study aimed to evaluate the extent of microleakage of a single type of composite resin (Clearfil Majesty Posterior, Kuraray, Osaka, Japan) following different preheating procedures in Class $V$ cavities prepared with a diamond bur or Er:YAG (erbium: yttrium aluminum garnet) laser.

Methods: The study randomly divided 72 permanent molar teeth divided into eight groups $(\mathrm{n}=9)$ : G1: Diamond bur-unheated composite resin (room temperature-24 ${ }^{\circ} \mathrm{C}$ ); G2: Diamond bur-composite preheated to $37{ }^{\circ} \mathrm{C}$; $\mathrm{G} 3$ : Diamond bur-composite preheated to $54{ }^{\circ} \mathrm{C}$; G4: Diamond bur-composite preheated to $68^{\circ} \mathrm{C}$; G5: Er:YAG laser-unheated composite resin (room temperature-24 ${ }^{\circ} \mathrm{C}$ ); G6: Er:YAG laser-composite preheated to $37^{\circ} \mathrm{C}$; G7: Er:YAG laser-composite preheated to $54^{\circ} \mathrm{C}$; and G8: Er:YAG laser-composite preheated to $68^{\circ} \mathrm{C}$. The specimens were subjected to a thermal cycling regimen of 5000 cycles between 5 and $55^{\circ} \mathrm{C}$; then they were immersed in a solution of $0.5 \%$ basic fuchsin dye for 24 hours. The dyed specimens were sectioned in the buccolingual direction and dye penetration was scored in a blinded manner using a five-point qualitative scale. Microleakage scores were analyzed with the Kruskall-Wallis, Mann-Whitney U, and Wilcoxon tests.
\end{abstract}

Results: There were no statistically significant differences between the microleakages of composite applied to cavities prepared by either the Er:YAG laser or diamond bur $(P>05)$. Statistical analysis revealed significant differences between the enamel and dentin in all restorations $(P<.001)$. However, there were no significant differences among the preheated groups ( $P>$.05).

Conclusions: For all groups, microleakage values were higher at gingival margins than at occlusal margins. The use of the Er:YAG laser at different preheating procedures did not influence the marginal sealing in Class V composite resin restorations. (Eur J Dent 2012;6:87-94)

Key words: Er:YAG laser, microleakage, preheated composite resin.

1 Department of Operative Dentistry, Faculty of Dentistry, Gaziantep University, Gaziantep, TURKIYE.

2 Department of Prosthodontics, Faculty of Dentistry, Bezmialem Vakif University, Istanbul, TURKIYE.

${ }^{3}$ Department of Operative Dentistry, Faculty of Dentistry, Selcuk University, Konya, TURKIYE.
Corresponding author: Dr. Emine Sirin Karaarslan Department of Operative Dentistry, Faculty of Dentistry, Gaziantep University, Kampus, Gaziantep, TURKIYE. Phone: +90 3423606060 ext-76614

Fax: +903423610610

e-mail: karaarslan.eminedgmail.com 


\section{INTRODUCTION}

Composite resins are routinely used as restorative materials in anterior and posterior teeth due to the resins' excellent aesthetics, ${ }^{1}$ their strong mechanical and physical properties, ${ }^{2}$ and their high resistance to dissolution. ${ }^{3}$ However, despite improvements in resin composite formulations over the years, polymerization shrinkage of the resin matrix is still considered problematic due to unsuccessful direct composite resin restorations. ${ }^{4}$ The high viscosity and stickiness of the highly filled composite makes insertion and adaptation of the material to the preparation walls difficult. ${ }^{5}$ Poor adhesion between the dentin and restorative material causes gap formation. Ultimately, marginal gap formation leads to microleakage, which may be responsible for increased postoperative sensitivity, pulpal inflammation, staining, and recurrent caries. ${ }^{6,7}$ To receive an excellently sealed, longterm restoration, material adaptation to the cavity walls is important. 8

The preheating of resin systems has many benefits. For example, the flow of hybrid composites can be greatly increased by preheating. The increased flow can improve the adaptation of the prepared tooth walls, which in turn may reduce microleakage. ${ }^{9}$ Uctasli et al ${ }^{10}$ stated that preheating the treatment did not change the mechanical properties of the composite resin materials so the tested composite resin materials could be preheated because of the clinical advantages like more adaptation to the cavity walls.

Heating the resin composite prior to placement and polymerizing also increases monomer conversion. ${ }^{11}$ With increased paste temperature, free radicals and increasing polymer chains become more fluid as a consequence of decreased paste viscosity and they react to a greater extent, resulting in a more complete polymerization reaction and greater crosslinking. The increase in polymerization may lead to improved mechanical properties and increased wear resistance. ${ }^{12}$

Preheating devices are commercially used at a temperature range of $54-68^{\circ} \mathrm{C}$, which is questioned regarding pulp compatibility in deep cavities. Nevertheless, only a $0.8^{\circ} \mathrm{C}$ temperature increase was found after placement of $60^{\circ} \mathrm{C}$ heated composite, but there was a $5^{\circ} \mathrm{C}$ increase upon $20 \mathrm{~s}$ light-curing. ${ }^{13}$
Pretreatment of the tooth surface, especially caries removal, is essential for the establishment of a strong bond between the resin and both enamel and dentine. ${ }^{14}$ Lasers have now been demonstrated to be highly effective for in vitro caries removal. ${ }^{15}$ The advantages of laser use, including decreased disturbance and reduced pain, are now drawing many researchers to investigate a multitude of applications for lasers in dentistry. Highintensity lasers have now been extensively used and approved for clinical use. The Er:YAG laser (2.94 $\mu \mathrm{m})$ is particularly attractive as its wavelength has the highest absorption by water of any wavelength in current use, and it also has a high affinity for hydroxyapatite. ${ }^{16}$

In the classical diamond bur preparation, a smear layer remains on the dentine. This smear layer consists of freshly cut tooth structure or tooth debris that forms a coating and becomes smeared on the surface of the preparation. Cavity preparation produced by a handpiece bur is smooth in the enamel and dentine surface. ${ }^{17}$ In contrast, the Er:YAG laser exposes a typical intertwined patterned surface with open dentin tubuli. ${ }^{18}$ Moreover, this ablation process leaves no hydroxyapatite-depleted collagen on the surface, unlike acid-etching, which exposes a microporous demineralized collagen fibril tissue that can be hybridized using conventional resin-based adhesives. ${ }^{19}$

The aim of the present study was to evaluate the microleakage of a single type of resin composite following different resin preheating procedures and associated self-etch adhesive systems in Class V cavities prepared by either Er:YAG laser or a high-speed dental bur. The research hypothesis was that the composite with the highest preheating temperature would have the lowest microleakage scores for both laser and bur prepared cavities.

\section{MATERIALS AND METHODS}

Tooth Selection

With approval from the Ethics Committee of the Faculty of Dentistry, Gaziantep University (Gaziantep, Turkeyl, seventy-two extracted caries and restoration-free permanent human molars were selected and stored in distilled water at $4^{\circ} \mathrm{C}$ for a maximum of 3-4 weeks. The teeth were cleaned with slurry of pumice and water, rinsed thoroughly with tap water, and then examined macroscopi- 
cally with magnification for defects in the enamel and dentin.

\section{Sample Preparation}

The teeth were randomly assigned into eight groups of nine teeth each. One Class V preparation was made in each tooth. Class $V$ cavities were prepared on the buccal surfaces with the occlusal margins in enamel and the gingival margins located $1.5 \mathrm{~mm}$ apical to the cemento-enamel junction. Cavity dimensions were standardized, $14.0 \mathrm{~mm}$ in width, $3.0 \mathrm{~mm}$ in height, and $2 \mathrm{~mm}$ in depth) using a marked bur.

In Groups 1-4, the cavities were prepared with a diamond straight cylinder (008) bur in an air turbine handpiece. These groups were as follows:

Group 1: Unheated composite resin-room temperature $\left(24^{\circ} \mathrm{C}\right)$ composite-control group;

Group 2: Composite preheated to $37^{\circ} \mathrm{C}$;

Group 3: Composite preheated to $54^{\circ} \mathrm{C}$; and

Group 4: Composite preheated to $68^{\circ} \mathrm{C}$.

An Er:YAG laser (Fidelis plus III, Fotona, 1210 Ljubljana, Slovenial was used for cavity preparation in Groups 5-8. The non-contact handpiece (R02) was used at $9.00 \mathrm{~W}$ for enamel and $4.00 \mathrm{~W}$ for dentin with very short pulse mode. It operated at a wavelength of $2.94 \mu \mathrm{m}$; the repetition rate was $30 \mathrm{~Hz}$ for enamel and $20 \mathrm{~Hz}$ for dentin. The air was adjusted to the " 8 " and air was adjusted to " 4 " on the scale of the laser unit. These groups were as follows:

Group 5: Unheated composite resin-room temperature $\left(24^{\circ} \mathrm{C}\right)$ composite-control group;

Group 6: Composite preheated to $37^{\circ} \mathrm{C}$;

Group 7: Composite preheated to $54^{\circ} \mathrm{C}$; and

Group 8: Composite preheated to $68^{\circ} \mathrm{C}$. ray, Kuraray Medical, Osaka, Japan). The adhesive used was a bonding agent with $10 \%$ microfiller that consists of two bottles: a self-etching primer and a light-cured bonding resin (Clearfil SE Bond, Kuraray). The adhesive used was described in Table 1. Cavities were filled following the manufacturer's instructions for use. The Quartz Tungsten Halogen (Hilux 250, $550 \mathrm{~mW} / \mathrm{cm}^{2}$, Benlioglu Dental, Turkey) was used for polymerization. The filling material was placed at approximately $2 \mathrm{~mm}$ increments. For this, three oblique increments were used and each increment was cured for $40 \mathrm{~s}$. The first increment was placed on the axial and mesial cavity walls, the second on the axial and distal cavity walls, and the last increment completely filled the cavity. In the preheated groups, all composite increments were preheated.

Composite resins in the preheated groups were placed in a unit (Calset ${ }^{\mathrm{TM}}$, AdDent Inc., Danbury, CT, USAl set to a temperature of 37,54 , or $68^{\circ} \mathrm{C}$. This unit was used with the standard tray that heats seven holes. For restorations utilizing the preheated composite, the composite tube was inserted into the hole and composite resin was respectively heated to a temperature of 37,54 , or $68^{\circ} \mathrm{C}$, and then placed immediately into the tooth cavity after removing the resin from the Calset unit. A previous study has shown that there is an approximate $25^{\circ} \mathrm{F}$ decrease in temperature in the 2 min after removing the composite resin from the heating unit. ${ }^{8}$ Therefore, it is important to place the composite as quickly as possible.

The surfaces of the restorations were finished with finishing diamonds (Finishing diamond, Diatech Dental AC, Heerbrugg, Switzerland) and polished with aluminum oxide polishing disks (SofLex, 3M ESPE Dental Products, St. Paul, MN, USA). All specimens were then stored in distilled water at room temperature $\left(24^{\circ} \mathrm{C}\right)$ for 24 hours.

Table 1. Application protocol of adhesive system

\begin{tabular}{|c|c|c|c|c|}
\hline Material, Abbreviation & Classification & Composition & Steps & Directions for use \\
\hline Clearfil $^{\mathrm{TM}}$ SE Bond & \multirow{4}{*}{$\begin{array}{l}\text { Two-Step- } \\
\text { Self-Etching } \\
\text { Type } 3\end{array}$} & Primer: MDP, water, ethanol, , & Self-etching & Apply primer using slight agitation \\
\hline & & hydrophilic dimethacrylate, HEMA & primer & for20 s; air-dry gently \\
\hline Lot no Primer ; 008669A & & & & Apply bonding and spread with a \\
\hline Lot no Bonding; 01276A & & $\begin{array}{c}\text { Bonding: HEMA, MDP, hydrophobic } \\
\text { dimethacrylate, bis-GMA, silica }\end{array}$ & Adhesive & $\begin{array}{c}\text { gently air stream; polymerize } 10 \mathrm{~s}, \\
\text { place composite resin and polymer- } \\
\text { ize } 40 \mathrm{sn}\end{array}$ \\
\hline
\end{tabular}

\section{Restoration Procedure}

In this study, all cavities were treated with composite resin (Clearfil Majesty Posterior, Kura-

\section{Microleakage Test}

The specimens were thermocycled 5000 times between water baths at $5^{\circ} \mathrm{C}$ and $55^{\circ} \mathrm{C}$ with a dwell 
time in each bath of $15 \mathrm{~s}$ and transfer time $5 \mathrm{~s}$. The teeth were then dried superficially and the apex of each tooth was sealed with epoxy cement. The exposed crown and root structure was covered with two coats of nail varnish, leaving a $1 \mathrm{~mm}$ window around the cavity margins. The specimens were then immersed in a solution of $0.5 \%$ basic fuchsin dye for 24 hours to produce a visible stain. After this procedure, any surface-adhered dye was carefully rinsed away with tap water. Dye penetration around the specimens was used to determine the presence of a gap around the restoration.

To measure the vertical extent of microleakage, the teeth were bisected longitudinally through the restorations in a buccolingual direction with a low speed diamond saw (IsoMet, Buehler Ltd., Lake Bluff, IL, USA). The sectioned teeth were evaluated with a stereomicroscope (Olympus SZ4045 TRPT, Osaka, Japan) at $40 \mathrm{X}$ final magnification. The degree of microleakage determined through

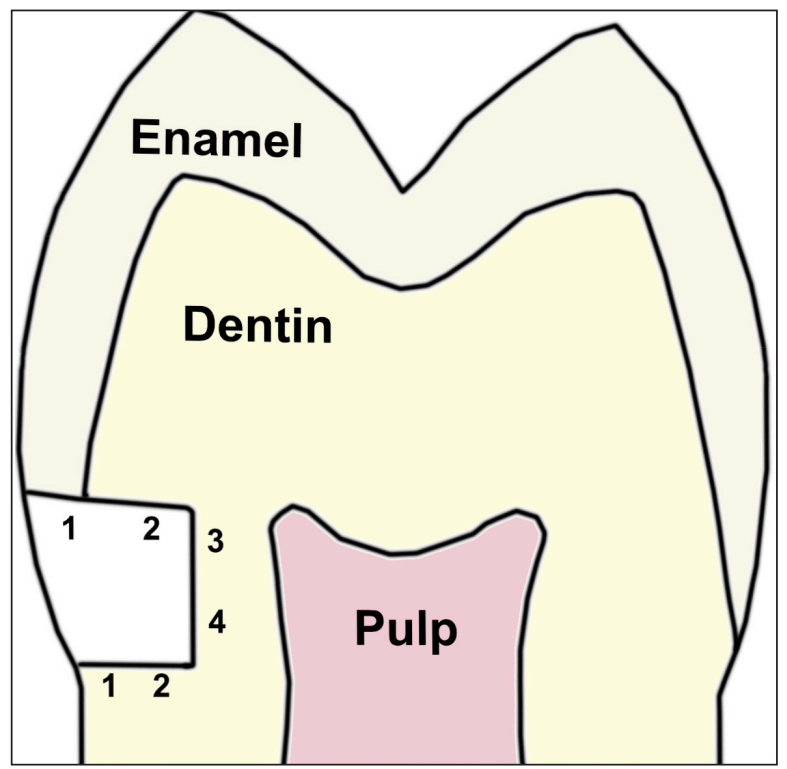

Figure 1. Degree of penetration between restoration and tooth.

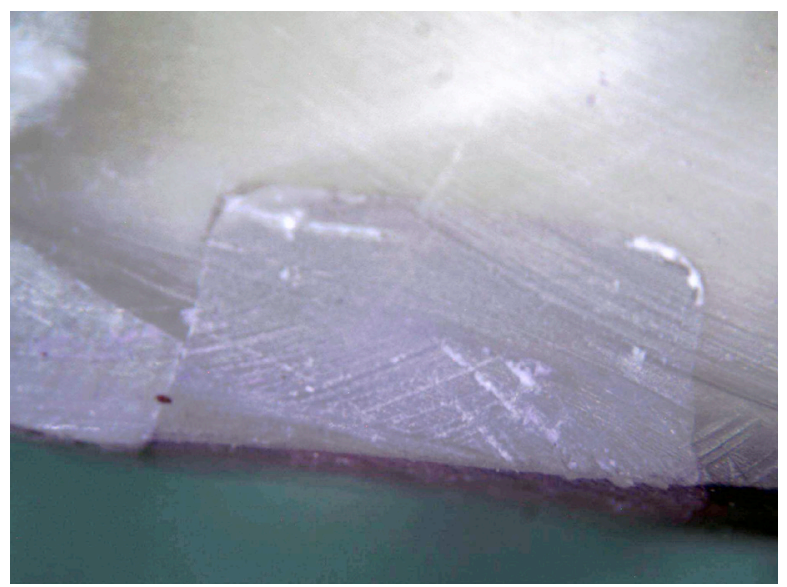

Figure 2. Stereomicroscopic image of cavity prepared with bur. dye penetration was scored according to standardized criteria (0 to 4; Table 2, Figure 1).20 Double blinded evaluators measured the slices and then the Kappa test was performed. Differences in the frequency distribution of scores between groups were assessed using the Kruskal-Wallis test and assessments within the groups were assessed using the Mann-Whitney $U$ test. The results of testing were analyzed with statistical software ISPSS/PC, Vers.16; SPSS, Chicago, IL, USA).

\section{RESULTS}

The frequency distribution of different degrees of microleakage in the groups is shown in Tables 3. Group numbers (1-8) indicate composite resin preheating numbers and cavity preparations. There were significant differences between the microleakage scores for the enamel and dentin $(P<.05)$.

Less microleakage was observed at the occlusal margins than at the cervical margins. No restorations showed microleakage at the enamel-restoration or dentin-restoration along the cavity wall or the axial wall at the occlusal margins. There were no significant differences between laser prepared and diamond bur prepared cavities ( $P>$.05). In all restorations, there were no significant differences among the preheated groups ( $P>$.05).

There were no significant differences in diamond bur prepared cavities at the gingival or occlusal margins among the preheated groups (P> 0.05). Likewise, there were no significant differences in laser prepared cavities at the gingival or occlusal margins among the preheated groups (P>.05).

The highest microleakage scores were detected in laser prepared dentin cavities with resin at $37^{\circ} \mathrm{C}$ and in diamond bur prepared cavities with

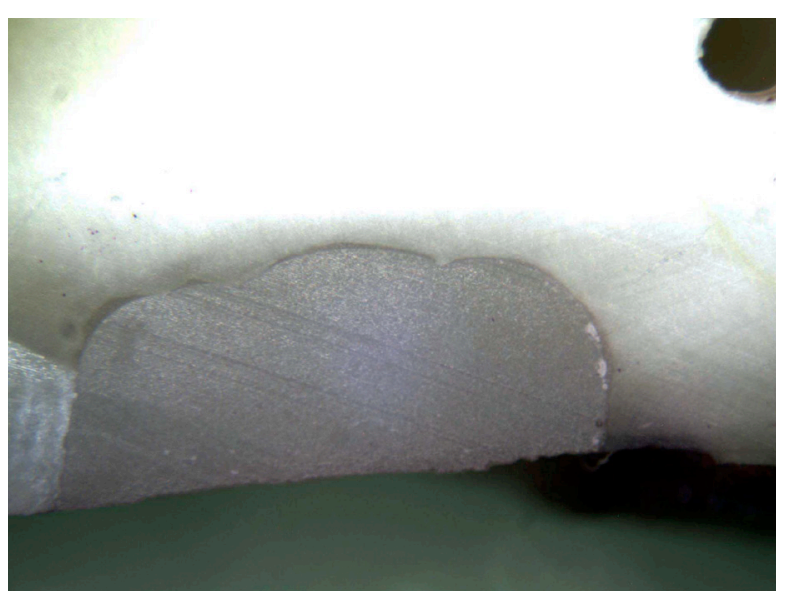

Figure 3. Stereomicroscopic image of cavity prepared with laser.

European Journal of Dentistry 
resin at room temperature $(P<.05)$. Figures 2 and 3 depict representative stereomicroscopic images of cavity preparation types and adhesive used.

\section{DISCUSSION}

The purpose of this in vitro study was to compare the microleakage of a single type of resin composite following different preheating procedures in Class $V$ cavities prepared by either the Er:YAG laser or high-speed dental diamond bur. The research hypothesis was that the composite with the highest preheating temperature would have the lowest microleakage scores for both laser and bur prepared cavities. But, the differences between the microleakage scores at the highest temperature of preheated composite in laser and bur prepared cavities were not statistically significant. Thus, the original hypothesis of the present study was rejected. This can be explained by the rapid drop in composite temperature during placing and contouring, also previously mentioned by Daronch et $\mathrm{al}^{8}$ It takes almost 2 min to complete the steps from removing the composite from the Calset device to full cavity filling. It is predicted that when a composite is heated up to $60^{\circ} \mathrm{C}$ and removed from the device, its temperature drops around $35-40 \%$ after $40 \mathrm{~s} .{ }^{8}$

The specimens were preheated with a preheating unit (Calset ${ }^{\top M}$, AdDent Inc., Danbury, CT, USA). There are only three different temperatures for this unit. Lohbauer et al. used from 10 to $68^{\circ} \mathrm{C}$ temperatures in their study. ${ }^{21}$ Fróes-Salgado et al. used the preheating unit Calset device (AdDent Inc., Danbury, CT, USA) at $68^{\circ} \mathrm{C}$ in their study. ${ }^{22}$

External composite heating at $54^{\circ} \mathrm{C}$ has been reported to significantly increased monomer conversion compared to room temperature composite. ${ }^{23}$ However, Silikas et $\mathrm{al}^{24}$ reported that the higher the degree of conversion in resin composites, the higher is the polymerization shrinkage. Polymerization shrinkage, along with thermal contraction, might create high interfacial stresses in preheated composites upon thermal equilibrium with harmful effects on marginal adaptation, integrity, and seal. ${ }^{25}$ Fróes-Salgado et al ${ }^{22}$ reported that a preheating treatment prior to light polymerization, similar to a clinical situation, did not alter the mechanical properties and monomer conversion of the composite but, instead, provided enhanced composite adaptation to cavity walls.
Wagner et $\mathrm{al}^{26}$ reported that a preheating treatment resulted in significantly less microleakage at the cervical margin compared to the other groups and that preheated composite was a valuable adjunct for reducing microleakage. According to the results of this study, no statistically significant difference was found between the preheated groups and the control group (unheated composite) in cervical or occlusal margins. It should be recommended that preheated composite resin be lightcured immediately after placement without any delay.

Some studies have described the surface alterations of dental hard tissues after Er:YAG laser irradiation as appearing flaky and scaly or as having irregular surfaces, and these surfaces are thought to be more suitable for composite resin restorations. ${ }^{16,} 27-30$ Hossain et $\mathrm{al}^{31}$ reported that enamel and dentin surfaces treated with Er:YAG laser irradiation were capable of decreasing the microleakage of composite resin restorations. Cavities prepared with a high-speed diamond bur have a layer of debris. This smear layer can be removed or modified to achieve micromechanical retention of composite resin material to the dental substrate $^{32}$, depending on the adhesive protocol used. According to the results of the present study, the performance of the Er:YAG laser, judging by microleakage scores, was similar to that of the diamond bur for Class V cavities; no significant differences were found between the laser and bur cavities, as in agreement with previous studies using the Er:YAG laser. ${ }^{30}$

A study by Attar et a ${ }^{33}$ compared microleakages at the occlusal and cervical margins following the use of the Er:YAG laser for cavity preparation with different parameters and adhesive systems. They reported higher levels of microleakage in the gingival margins in all groups. Roebuck et $\mathrm{al}^{34}$ found microleakages in all groups at both the enamel and the dentin margins. They reported that levels of microleakage were statistically insignificant for both enamel and dentin, except for the $240 \mathrm{~mJ}$ treated enamel margins. This group performed better than the other groups. In another study, Delme et $\mathrm{al}^{14}$ found no statistically significant differences in microleakage between the occlusal and gingival walls in groups where cavities were Er:YAG-lased and laser-etched and where no acid-etching was used. Moldes et $\mathrm{al}^{35}$ reported that 
a significantly lower degree of microleakage was observed when a self-etching adhesive system was used for cavities prepared with both Er:YAG and Er,Cr:YSGG lasers in comparison with an etchand-rinse adhesive system. This can be explained by the ablation of enamel and dentin substrates produced by erbium lasers, which create retentive patterns, absence of a smear layer, and morphological and possibly chemical changes in inorganic and/or organic content of hard tissue. After laser irradiation, there is better interaction and supposed chemical linking of acidic resin monomers with dental substrate residues/by products. ${ }^{31}$

The self-etching technique simplifies toothtissue conditioning with acidic hydrophilic monomers. Special bi-functional monomers are used for this purpose. Most products involve bonding bivalent alcohol groups with methacrylic acid and phosphoric acid via ester bonds, or they contain 4-META (4-methacryloyloxethyl trimellitic acid) or MDP (methacryloyloxy-decyldihydrogenphosphate) as conditioning components. ${ }^{36}$

Current two-step self-etching primers or single-step self-etching adhesives produce simultaneous conditioning and priming effects on dental substrates. ${ }^{37}$ These systems do not remove the smear layer, instead, modify it and penetrate and the subjacent enamel and dentin, creating a thin hybrid layer ${ }^{37}$ dependent on $\mathrm{pH}$, composition, and

\begin{tabular}{ll} 
Table 2. Scoring criteria at occlusal and gingival margins. \\
\hline 0 & No dye penetration \\
1 & Dye penetration up to one-half the cavity wall \\
\hline 2 & Dye penetration up to total cavity wall \\
3 & Dye penetration up to one-half the axial wall \\
4 & Dye penetration more than one-half the axial wall \\
\hline
\end{tabular}

Table 3. Frequency distribution of microleakage for different groups.

\begin{tabular}{|c|c|c|c|c|c|c|c|c|c|c|}
\hline \multirow[t]{2}{*}{ Groups } & \multicolumn{5}{|c|}{ Occlusal } & \multicolumn{5}{|c|}{ Gingival } \\
\hline & 0 & 1 & 2 & 3 & 4 & 0 & 1 & 2 & 3 & 4 \\
\hline 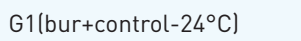 & 8 & 1 & 0 & 0 & 0 & 5 & 2 & 0 & 0 & 2 \\
\hline $\mathrm{G} 2$ (bur+preheated $-37^{\circ} \mathrm{C}$ ) & 9 & 0 & 0 & 0 & 0 & 7 & 0 & 1 & 0 & 1 \\
\hline $\mathrm{G} 3\left(\right.$ bur+preheated $-54^{\circ} \mathrm{C}$ ) & 9 & 0 & 0 & 0 & 0 & 7 & 0 & 0 & 2 & 0 \\
\hline $\mathrm{G} 4\left(\right.$ bur+preheated $\left.-68^{\circ} \mathrm{C}\right)$ & 9 & 0 & 0 & 0 & 0 & 8 & 0 & 0 & 1 & 0 \\
\hline Total(bur) & 35 & 1 & 0 & 0 & 0 & 27 & 2 & 1 & 3 & 3 \\
\hline $\mathrm{G} 5$ (laser+control-24${ }^{\circ} \mathrm{C}$ ) & 7 & 2 & 0 & 0 & 0 & 6 & 2 & 1 & 0 & 0 \\
\hline G6(laser+preheated $-37^{\circ} \mathrm{C}$ ) & 9 & 0 & 0 & 0 & 0 & 4 & 0 & 3 & 0 & 2 \\
\hline G7(laser+preheated $-54^{\circ} \mathrm{C}$ ) & 9 & 0 & 0 & 0 & 0 & 7 & 1 & 0 & 0 & 1 \\
\hline G8(laser+preheated $\left.-68^{\circ} \mathrm{C}\right)$ & 9 & 0 & 0 & 0 & 0 & 9 & 0 & 0 & 0 & 0 \\
\hline Total(laser) & 34 & 2 & 0 & 0 & 0 & 26 & 3 & 4 & 0 & 3 \\
\hline
\end{tabular}

European Journal of Dentistry concentration of polymerizable acids. ${ }^{38}$ The acidic monomers of self-etching adhesives promote conditioning of the smear layer and underlying enamel/dentin substrates, resulting in a typical hybrid layer,' which is divided into an upper portion with a thick hybridized smear layer (resin infiltration into the demineralized organic material layer) and a lower portion with a thin and homogeneous true hybrid layer in the demineralized dental substrate. $^{39}$

In their study, Holzmeier et al $^{36}$ reported that Clearfil ${ }^{\mathrm{TM}}$ S3 Bond, Clearfil'TM SE Bond, Clearfil'TM Protect Bond, AdheSE ${ }^{\circledR}$, and Xeno ${ }^{\circledR} I I I$ demonstrated comparatively less distinct enamel etching patterns, but their bonds were, surprisingly, not significantly different from those of Transbond ${ }^{\mathrm{TM}}$ Plus SE Primer, whose etching pattern was the most distinctive among the self-etching primers. Vicente et al ${ }^{40}$ reported that the conditioning effect of Transbond ${ }^{T M}$ Plus SE Primer was similar to that of phosphoric acid-etching. These studies show activities of self-etching adhesive systems. In the current study, we used ClearfilTM SE Bond.

Moldes et $\mathrm{al}^{35}$ used the etch-and-rinse twostep adhesive system and the self-etch adhesive system in their microleakage study. They reported that neither the occlusal nor the enamel margins demonstrated differences in microleakage for any of the treatments. In the current study, two-step self etch adhesive system was used and less microleakage was observed at the occlusal or enamel margins than at the gingival or dentin margins. There were no significant differences for all groups in regards to the occlusal or enamel margins.

Wagner et $\mathrm{al}^{26}$ reported statistically different amounts of microleakage between the cervi- 
cal and occlusal margins in Class II cavities. They stated that better sealed interfaces were formed at the occlusal margins than at the cervical margins. The most accepted theory is that the greater amount of enamel at the occlusal margins allows for better sealing and reduced microleakage. ${ }^{26}$ However, the geometry of the restoration may also have been important; the longer vertical dimension would result in more composite shrinkage in that direction. In another study, Küçükeșmen and Sönmez ${ }^{41}$ stated that more microleakage was observed in cervical margins than occlusal margins. In the current study, less microleakage was observed at the occlusal margins compared to the cervical margins. No restorations showed microleakage at the enamel-restoration and dentinrestoration along the cavity and axial walls at the occlusal margins.

In the present study, dye penetration was chosen because it had previously provided a simple, inexpensive quantitative and comparable method for evaluating various composite restorations. ${ }^{42}$ The results of the study may not be directly extrapolated to the clinical environment. Additional laboratory and clinical studies that evaluate the microleakage of preheated composite resins in Class $V$ cavities should be performed to verify the results reported here.

\section{CONCLUSIONS}

Microleakage values were higher at gingival margins than at occlusal margins. The use of the Er:YAG laser at different preheating procedures did not influence the marginal sealing in class $\mathrm{V}$ composite resin restorations. Further studies should be continued and extended to include preheated composite resins.

Conflict of Interest: Authors indicate that they have not a financial relationship with the organization that sponsored the research. The authors declare that they have no conflict of interest.

\section{REFERENCES}

1. Burgess JO. Dental materials for the restoration of root surface caries. Am J Dent 1995;8:342-351.

2. Ferracane JL, Condon JR. Post-cure heat treatments for composites: properties and fractography. Dent Mater 1992;8:290-295
3. Htang A, Ohsawa M, Matsumoto $H$. Fatigue resistance of composite restorations: effect of filler content. Dent Mater 1995; 11:7-13.

4. Carvalho RM, Yoshiyama M, Pashley EL, Pashley DH. In vitro study on the dimensional changes of human dentine after demineralization. Arch Oral Biol 1996;41:369-377.

5. Strassler HE, Trushkowsky RD. Predictable restoration of Class 2 preparations with composite resin. Dent Today 2004;23:93-99.

6. Kidd EA. Microleakage: a review. J Dent 1976;4:199-206.

7. Lohbauer U, Rahiotis C, Kramer N, Petschelt A, Eliades G. The effect of different light-curing units on fatigue behavior and degree of conversion of a resin composite. Dent Mater 2005;21:608-615.

8. Daronch M, Rueggeberg FA, Moss L, de Goes MF. Clinically relevant issues related to preheating composites. $J$ Esthet Restor Dent 2006;18:340-350.

9. Lovell LG LH, Elliot JE, Bowman CN. Understanding the kinetics and network formation of dimethacrylate dental resins. Polymer Adv Techn 2001;12:335-345.

10. Uctasli MB, Arisu HD, Lasilla LV, Valittu PK. Effect of preheating on the mechanical properties of resin composites. Eur J Dent 2008;2:263-268.

11. Daronch M, Rueggeberg FA, De Goes MF, Giudici R. Polymerization kinetics of pre-heated composite. J Dent Res 2006;85:38-43.

12. Daronch M, Rueggeberg FA, De Goes MF. Monomer conversion of pre-heated composite. J Dent Res 2005;84:663-667.

13. Daronch M, Rueggeberg FA, Hall G, De Goes MF. Effect of composite temperature on in vitro intrapulpal temperature rise. Dent Mater 2007;23:1283-1288.

14. Delme KI, Deman PJ, De Moor RJ. Microleakage of class V resin composite restorations after conventional and Er:YAG laser preparation. J Oral Rehabil 2005;32:676-685.

15. Goldman L, Gray JA, Goldman J, Goldman B, Meyer R. Effect of Laser Beam Impacts on Teeth. J Am Dent Assoc 1965;70:601-606.

16. Keller U, Hibst R. Experimental studies of the application of the Er:YAG laser on dental hard substances: II. Light microscopic and SEM investigations. Lasers Surg Med 1989;9:345351.

17. Quo BC, Drummond JL, Koerber A, Fadavi S, Punwani I. Glass ionomer microleakage from preparations by an $\mathrm{Er} /$ YAG laser or a high-speed handpiece. J Dent 2002;30:141146.

18. Kameyama A, Kawada E, Takizawa M, Oda Y, Hirai Y. Influence of different acid conditioners on the tensile bond strength of 4-META/MMA-TBB resin to Er:YAG laser-irradiated bovine dentin. $J$ Adhes Dent 2000;2:297-304. 
19. Van Meerbeek B, Yoshida Y, Lambrechts $P$, et al. A TEM study of two water-based adhesive systems bonded to dry and wet dentin. J Dent Res 1998;77:50-59.

20. Ozturk AN, Ozturk B, Aykent F. Microleakage of different cementation techniques in Class V ceramic inlays. J Oral Rehabil 2004;31:1192-1196.

21. Lohbauer U, Zinelis S, Rahiotis C, Petschelt A, Eliades G. The effect of resin composite pre-heating on monomer conversion and polymerization shrinkage. Dent Mater 2009;25:514-519.

22. Froes-Salgado NR, Silva LM, Kawano Y, Francci C, Reis A, Loguercio AD. Composite pre-heating: effects on marginal adaptation, degree of conversion and mechanical properties. Dent Mater 2010;26:908-914.

23. Trujillo M, Newman SM, Stansbury JW. Use of near-IR to monitor the influence of external heating on dental composite photopolymerization. Dent Mater 2004;20:766-777.

24. Silikas N, Eliades G, Watts DC. Light intensity effects on resin-composite degree of conversion and shrinkage strain. Dent Mater 2000;16:292-296.

25. Braga RR, Ballester RY, Ferracane JL. Factors involved in the development of polymerization shrinkage stress in resin-composites: a systematic review. Dent Mater 2005;21:962-970.

26. Wagner WC, Asku MN, Neme AM, Linger JB, Pink FE, Walker $\mathrm{S}$. Effect of pre-heating resin composite on restoration microleakage. Oper Dent 2008;33:72-78.

27. Armengol V, Jean A, Enkel B, Assoumou M, Hamel H. Microleakage of class $V$ composite restorations following Er:YAG and Nd:YAP laser irradiation compared to acidetch: an In vitro study. Lasers Med Sci 2002;17:93-100.

28. Hibst R, Keller U. Experimental studies of the application of the Er:YAG laser on dental hard substances: I. Measurement of the ablation rate. Lasers Surg Med 1989;9:338-344.

29. Khan MF, Yonaga K, Kimura Y, Funato A, Matsumoto K. Study of microleakage at Class I cavities prepared by Er:YAG laser using three types of restorative materials. $J$ Clin Laser Med Surg 1998;16:305-308.

30. Kohara EK, Hossain M, Kimura Y, Matsumoto K, Inoue M, Sasa R. Morphological and microleakage studies of the cavities prepared by Er:YAG laser irradiation in primary teeth. J Clin Laser Med Surg 2002;20:141-147.

31. Hossain M, Yamada Y, Nakamura Y, Murakami Y, Tamaki Y, Matsumoto K. A study on surface roughness and microleakage test in cavities prepared by Er:YAG laser irradiation and etched bur cavities. Lasers Med Sci 2003;18:25-31.

32. Tay FR, Pashley DH. Aggressiveness of contemporary selfetching systems. I. Depth of penetration beyond dentin smear layers. Dent Mater 2001;17:296-308.
33. Attar N, Korkmaz Y, Ozel E, Bicer CO, Firatli E. Microleakage of class $V$ cavities with different adhesive systems prepared by a diamond instrument and different parameters of Er:YAG laser irradiation. Photomed Laser Surg 2008;26:585591.

34. Roebuck EM, Whitters CJ, Saunders WP. The influence of three Erbium:YAG laser energies on the in vitro microleakage of Class $\mathrm{V}$ compomer resin restorations. Int $J$ Paediatr Dent 2001;11:49-56.

35. Moldes VL, Capp Cl, Navarro RS, Matos AB, Youssef MN, Cassoni $A$. In vitro microleakage of composite restorations prepared by Er:YAG/Er,Cr:YSGG lasers and conventional drills associated with two adhesive systems. J Adhes Dent 2009;11:221-229.

36. Holzmeier M, Schaubmayr M, Dasch W, Hirschfelder U. A new generation of self-etching adhesives: comparison with traditional acid etch technique. J Orofac Orthop 2008;69:7893.

37. Moura SK, Pelizzaro A, Dal Bianco K, et al. Does the acidity of self-etching primers affect bond strength and surface morphology of enamel? J Adhes Dent 2006;8:75-83.

38. Pashley DH, Tay FR. Aggressiveness of contemporary selfetching adhesives. Part II: etching effects on unground enamel. Dent Mater 2001;17:430-444.

39. Miguez PA, Castro PS, Nunes MF, Walter R, Pereira PN. Effect of acid-etching on the enamel bond of two self-etching systems. J Adhes Dent 2003;5:107-112.

40. Vicente A, Bravo LA, Romero M, Ortiz AJ, Canteras M. Shear bond strength of orthodontic brackets bonded with self-etching primers. Am J Dent 2005;18:256-260.

41. Kucukesmen C, Sonmez H. Microleakage of class-v composite restorations with different bonding systems on fluorosed teeth. Eur J Dent 2008;2:48-58.

42. Korkmaz Y, Ozel E, Attar N. Effect of flowable composite lining on microleakage and internal voids in Class II composite restorations. J Adhes Dent 2007;9:189-194. 